\title{
EL PENSAMIENTO DE JOSÉ RIZAL
}

\section{THE THOUGHT OF JOSE RIZAL}

\section{AUTOR}

\section{Francisco Marín Calahorro}

Doctor en Ciencias de la Información por la. Universidad Complutense de Madrid y Licenciado en Derecho por la UNED (España)

fmartincalahorro@hotmail.com

\section{RESUMEN}

José Rizal fue condenado por ser, presuntamente, el autor de un levantamiento en Filipinas que se produjo en 1896 contra el Gobierno español. Rizal fue inocente, y la mayor labor que hizo fue aunar el espíritu nacional de un pueblo que estaba diluido.

\section{PALABRAS CLAVE}

José Rizal - Filipinas - Derechos politicos.

\section{ABSTRACT}

Jose Rizal was condemned for being allegedly the author of an uprising in the Philippines occurred in 1896 against the Spanish government. Rizal was innocent, and most work he did was to bring the national spirit of a town that was diluted.

\section{KEY WORDS}

Jose Rizal - Philippines - Politics rights. 


\section{ÍNDICE}

1. Biografía de un patriota

2. Su obra

3. Bibliografía

\section{Biografía de un patriota}

Rizal fue acusado, por el consejo de guerra que lo condenó a muerte en diciembre de 1896, de ser el autor del levantamiento que se produjo en Filipinas en agosto de aquel año contra el Gobierno Español. Nadie duda un siglo después que José Rizal fue víctima de una serie de circunstancias que le llevaron a morir fusilado el 30 de diciembre a extramuros de la ciudad de Manila, en la explanada de Bagumbayan, sin que hubiese tenido nada que ver con la organización de la rebelión dirigida por Andrés Bonifacio.

Rizal sólo fue, y no es poco, el escultor que recuperó y modeló para el futuro la conciencia nacional del pueblo filipino, que se había diluido en la corriente cultural generada durante más de tres siglos de dominación colonial española.

Hombre inteligente, observador sensible de los males de su pueblo y preparado culturalmente. No en vano recibió en aulas españolas los conocimientos del momento. Primero en Filipinas -Ateneo Municipal de Manila, (Bachiller en Artes)recogido por los Padres J esuitas y en la Universidad de Santo Tomás dirigida por los Dominicos -Filosofía y Medicina- y más tarde en Madrid donde se licenció en Medicina y Filosofía y Letras; a lo que hay que sumar la experiencia europea de las 
corrientes intelectuales de la época, durante su estancia en varios países del continente. Rizar por su formación es una síntesis cultural de España y Europa.

Viaja a la península y Europa para descubrir si hay otro mundo diferente del que ahoga al indígena filipino. Le duele lo que observa en Filipinas:

"En nuestro pueblo veíamos la fuerza desenfrenada, las violencias y otros excesos cometidos por los que estaban encargados de velar por la paz pública; y, fuera, el bandolerismo, los tulisanes, contra los cuales eran impotentes nuestras autoridades. Dentro teníamos la tiranía y fuera el cautiverio. Y me preguntaba entonces si en los países que había allá, al otro lado del lago, se vivía de la misma manera; si allá se atormentaba con duros y crueles azotes al campesino sobre quien recaía una simple sospecha; si allá se respetaba el hogar; si para vivir en paz había que sobornar a todos los tiranos..."

Político eminente, se hace escritor y periodista para presentar sus ideas y propagarlas. No tuvo otros objetivos que elevar a su patria y a su pueblo a la altura de los países más avanzados de su tiempo. Así lo reconoce el periódico La Independencia en el número dedicado a homenajear su figura en 1898: "¿Que ha sido toda su vida? La campaña infatigable y honrada del político de alto vuelo que, en aras del amor a su país, ha jurado darle días de grandeza y felicidad".

Su campo de batalla no es otro que el papel impreso, es un hombre de ideas y sus armas son las palabras. Pretende alcanzar los objetivos políticos y, para él, el mejor camino es transmitir su pensamiento. Se hace escritor $\mathrm{y}$, como reconoce Unamuno, su heroísmo fue el heroísmo del escritor: "Pero entiéndase bien que no del escritor profesional, no del que piensa ó siente para escribir, sino del hombre henchido de amores que escribe porque ha pensado ó ha sentido". 
Sus escritos están impregnados de ideas liberales, de la defensa de la dignidad y de los derechos del hombre, de la igualdad de todos, independientemente de razas 0 procedencia. En Rizar prima el mundo de las ideas, pero no es un propagandista nato como lo fue José Martí, ni compuso proclamas o escritos políticos como éste y tampoco fue el orador que conmovía a su público como ocurría con el cubano. Apenas se conoce alguna pieza oratoria al Gran Tagalo; quizás la única, y donde comienza a exponer su pensamiento político, se produce el 25 de junio de 1884, con ocasión del homenaje que los filipinos le ofrecieron en Madrid al pintor Juan Luna como reconocimiento al éxito de su obra Spoliarum. El auditorio estaba formado por políticos relevantes .Moret, Labra, Andrés Mellado, Morayta, etc.- y un nutrido grupo de pintores, escritores y periodistas, así como representantes de la colonia filipina.

La tesis central de ese discurso postula que Filipinas camina hacia la madurez $\mathrm{y}$, saliendo de su letargo histórico,

"vuelve a despertarse conmovida por el choque eléctrico que le produce el contacto con los pueblos occidentales, y reclama la luz, la civilización que un tiempo les legara, confirmándose así las leyes externas de la evolución constante, de las transformaciones, de la periodicidad, del progreso".

Planteado esto, después de hacer el panegírico de los pintores Luna e Hidalgo, también homenajeado, pasó a presentar una crítica sobre la actuación de algunos españoles en la colonia:

"Si la madre enseña al hijo su idioma para comprender sus alegrías, sus necesidades o dolores, España, como madre, enseña también su idioma a Filipinas, pese a la oposición de esos miopes y pigmeos que asegurando el presente, no alcanzan a ver en el porvenir, no pesan las consecuencias; nodrizas raquíticas, corrompidas y corruptoras, 
que tienen a apagar todo sentimiento legítimo que, pervirtiendo el corazón de los pueblos, siembran en ellos los gérmenes de las discordias para que se recoja más tarde el fruto, el anapelo, la muerte de las generaciones futuras".

Por último, para finalizar el discurso, define su visión peculiar de la relación entre españoles y filipinos, que son:

"dos razas que se aman y se quieren, unidas moral, social y políticamente, en el espacio de cuatro siglos, para que formen en el futuro una sola nación en el espíritu, en sus deberes, en sus miras, en sus privilegios", y, a continuación, brinda, entre otras cosas, "porque la madre España, solícita y atenta al bien de sus provincias, ponga pronto en práctica las reformas que largo tiempo medita; el surco está trazado y la tierra no es estéril".

\section{Su obra}

Rizal no piensa entonces en la independencia, su filosofía puede resumirse en cuatro palabras: provincia, sí; colonia, no. Pretende que se vuelva a la situación establecida en la Constitución de 1812, en que Filipinas es considerada como una provincia y tiene representantes en las Cortes españolas.

Su obra tiene desde ese momento un permanente fin político y su contenido cambia según evolucionan las ideas del autor. Así, en primer lugar, su novela Noli me tangere, publicado en 1887, de carácter costumbrista, pretende denunciar el estado de vida a que está sometido el indio filipino y hacer visible el, a su juicio, "cáncer social" que padece su patria. Así lo expone en la dedicatoria de la obra, que, como es natural, la dirige "A mi Patria". 
"Deseando tu salud, que es la nuestra, y buscando el mejor tratamiento, haré contigo lo que con sus enfermos los antiguos: exponíanlos en las gradas del templo, para que cada persona que viniese de invocar a la Divinidad les propusiese un remedio.

$Y$ a este fin, trataré de reproducir fielmente tu estado sin contemplaciones; levantaré parte del velo que cubre tus llagas, sacrificando a la verdad de todo, hasta el mismo amor propio, pues, como hijo tuyo, adolezco también de tus defectos y flaquezas".

Con Noli me tangere pretende movilizar al pueblo filipino para que reivindique el reconocimiento de los derechos que le corresponden y que se preconizan, para todos los hombres, en los ideales liberales de la época; quiere que se den cuenta de la realidad en que viven y para ello lo coloca frente al espejo. El siguiente objetivo es que tome conciencia de lo que representa como pueblo con un pasado, que ha sido casi borrado por la colonización. También aprovecha la obra para dar su opinión de España y se pregunta si ies acaso incompatible el amor a su país con el amor a España? La respuesta es categórica:

"Amo a mi patria filipina, porque a ella le debo mi vida y felicidad, y porque todo hombre debe amar a su patria; amo a España, patria de mis mayores, porque a pesar de todo Filipinas le debe y le deberá su felicidad y porvenir".

Para este segundo objetivo utiliza, en 1889, la reimpresión que hace los Sucesos de las Islas Filipinas de Morga. Su fin es dar a conocer su pasado a los filipinos, para que recuperen su historia, puedan juzgar mejor el presente y medir el camino recorrido durante los tres siglos de dominación española. Así lo anuncia en su llamada A los filipinos en la introducción que hace a la obra: 
"Nacido y criado en el desconocimiento de nuestro Ayer, como casi todos vosotros, sin voz ni autoridad para hablar de lo que no vimos ni estudiamos, consideré necesario invocar el testimonio de un ilustre Español que rigió los destinos de Filipinas en los principios de su nueva Era y presenció los últimos momentos de nuestra antigua civilización. Es, pues, la sombra de la civilización de nuestros antepasados la que ahora ante vosotros evocará el autor".

Quiere que los filipinos encuentren sus raíces.

Pero será en la prensa donde escribirá su principal ensayo político y planteará sus principales reivindicaciones. Lo hará en un periódico publicado por filipinos en España, La Solidaridad, y presentará un análisis de lo que, a su juicio, será Filipinas dentro de cien años. Es un estudio político-social sobre el porvenir de Filipinas, en el que se analizan diversas hipótesis de su visión de la posible evolución histórica de la zona -la cuenca del pacífico- y de la influencia en ésta de las naciones europeas con presencia colonial en ella- España, Francia, Inglaterra, Holanda-, de los dos colosos vecinos -China y Japón- y de dos potencias emergentes con intereses en ese área Alemania y Estados Unidos-. Conocedor de que Filipinas aún no está preparada para la independencia presupone los eventuales riesgos que debe afrontar en su camino para constituirse como nación libre y, con una visión de futuro, acierta en casi todo. Prevé que:

"si Filipinas consigue su independencia al cabo de luchas heroicas y tenaces, los filipinos pueden estar seguros de que ni Inglaterra, ni Alemania, ni Francia, y menos Holanda, se atreverán a recoger 10 que España no ha podido conservar", aunque intuye que "acaso la gran República Americana, cuyos intereses se encuentran en el Pacífico, y que no tiene participación en los despojos de Afrecha, piense un día en posesiones ultramarinas". 
El ensayo lo inicia, como en el libro de Morga, haciendo referencia al pasado filipino, recordando la desaparición, ante la influencia española, de las tradiciones y de la cultura autóctona filipina; este es uno de sus caballos permanentes de batalla, siente la pérdida de identidad de su raza y desea que se recupere a toda costa. Enseguida propone una serie de cuestiones, que él mismo considera difíciles de responder:

"¿Continuarán las Islas Filipinas como colonia española, y en ese caso, qué clase de colonia? ¿Llegarán a ser provincias españolas con o sin autonomía? Y para llegar a este estado, ¿qué clase de sacrificios tendrá que hacer?.

¿Se separarán tal vez de la Madre Patria para vivir independientes, para caer en manos de otras naciones o para aliarse con otras potencias vecinas?"

Al responder a estas preguntas y sacar sus propias conclusiones, Rizal, plantea y presenta sus propias ideas, su pensamiento del presente para el futuro, y sus conclusiones son:

1. Las Islas no pueden seguir en el estado en que están, deben recabar de la Metrópoli más libertades;

2. Querer que se mantenga la situación actual entraña riesgo de una revolución y una ruptura total. Por ello afirma rotundamente:

"Las Filipinas, pues, o continuarán siendo del dominio español, pero con más derechos y más libertades, o se declararán independientes, después de ensangrentarse y ensangrentar a la Madre Patria". 
No considera que la ocasión para la independencia está madura y se conforma con reivindicar prensa libre en las Islas y diputados filipinos en las Cortes españolas.

Reconoce que:

"éstas son las dos reformar fundamentales que, bien interpretadas y aplicadas, podrán disipar todas las nubes, afirmar el cariño a España y hacer fructiferas todas las posteriores (...) En suma: las Filipinas continuarán siendo españolas, si entran en la vía de la vida legal y civilizada, si se respetan los derechos de sus habitantes, si se les conceden los otros que se les deben, si la política liberal de los Gobierno se lleva a cabo sin trabas ni mezquindades, sin subterfugios ni falsas interpretaciones".

Es claro que propone la igualdad de trato con el resto de los territorios españoles y desea que éstos suceda mediante la concesión pacífica y no aboga por la insurrección armada, ya que:

"los que hoy luchamos en el terreno legal y pacífico de las discusiones, lo comprendamos así, y con la mirada fija en nuestros ideales, no cesaremos de abogar por nuestra causa, sin salir de los límites de lo legal".

Sin embargo, advierte que:

"si antes la violencia nos hace callar o tenemos la desgracia de caer (lo cual es posible, pues no somos inmortales), entonces no sabemos que camino tomarán los retoños numerosos y de mejor savia que se precipitarán para ocupar los puestos que dejemos vacíos". 
Las frases anteriores las escribe el 15 de diciembre de 1889, en paralelo casi con la publicación del libro de Morga; aún cree posible la convivencia y advierte del riesgo de llegar al enfrentamiento. La ruptura dialéctica se producirá apenas dos años después, en 1891, en su segunda novela El Filibusterismo. La causa es la incomprensión del gobierno español del momento.

El Filibusterismo es un desafío desde la portada a la última página. El reto comienza al situar en portada el breve prólogo de Blumentrit:

"Fácilmente se puede suponer que un filibustero ha hechizado en secreto a la liga de los fraileros y retrógrados para que, siguiendo inconscientes sus inspiraciones, favorezcan y fomenten aquella política que sólo ambiciona un fin: extender las ideas del filibusterismo por todo el país y convencer al último filipino de que no existe otra salvación fuera de la separación de la Madre Patria". Es el anuncio de que no queda otra solución que el separatismo.

Si Noli me Tangere tiene mucho de denuncia crítica, pero dentro del marco de lo que puede considerarse una novela costumbrista, El Filibusterismo es una llamada a la revolución por parte de su protagonista Simoun. Ya nada queda en su persona del idealista e ilustrado Ibarra, protagonista de la primera novela, que predica la concordia y la convivencia pacífica entre españoles y filipinos y que rechaza dirigir un movimiento revolucionario. Simoun es la imagen de la venganza, el espíritu de la revolución que sólo piensa ya en la independencia:

"(...) y en vez de tener aspiraciones de provincia, tenedlas de nación: en vez de pensamientos subordinados, pensamientos independientes, a fin de que ni por derechos, ni por costumbres, ni por lenguaje, el español se considere aquí como en su casa, ni ser considerado por el 
pueblo como nacional, sino siempre como invasor, como extranjero, y tarde o temprano tendréis vuestra libertad".

En ambas obras, Rizal utilizará los diversos recursos expresivos que ofrece el relato para transmitir su pensamiento e ideas. Los diálogos le permiten mostrar diferentes puntos de vista y debatir problemas para rebatir lo que no está de acuerdo, afianzar sus teorías y sacar conclusiones de la tesis general de la obra. Los comentarios son, para el autor, la técnica de estilo que emplea para enseñar su filosofía y política y presentarla y asumirla como propia, independiente de los personajes.

Para Retana,

"El Filibusterismo es el libro más nacionalista que he leído en mi vida. (...) Toda la obra es de un interés creciente. Pero en el buen entendimiento de que este interés no es el novelesco: el interés está en la doctrina que en cada momento va fluyendo en Rizal."

Sin embargo, el propio Retana concreta que, según manifestó por carta, al gobernador de Filipinas general Despujol, el señor Carnicero, que fue el encargado de la vigilancia de Rizal durante su deportación en Dapitán, el programa político de éste se resumía en los párrafos siguientes: 
1. "En primer término, dar al país representación en las Cortes, con lo cual cesarían los abusos que algunos cometen.

2. Secularizar a los frailes, haciendo cesar la tutela que sobre el Gobierno y el país ejercen estos señores, distribuir las parroquias, a medida que quedasen vacantes, entre los clérigos, que podrían ser tanto insulares como peninsulares.

3. Reformar la Administración en todas sus ramas. Fomentar la instrucción primaria, evitando toda la intervención de los frailes. Repartir en partes iguales, entre peninsulares e insulares, los empleos del país. Moralizar la Administración. Crear, en las capitales de provincias de más de 16.000 habitantes, Escuelas de Artes y Oficios. Libertad religiosa de imprenta".

Todo un abanico de reformas que nadie se planteó en el Gobierno de Madrid y que, tal vez, hubieran cambiado el desarrollo histórico de aquel "98".

Su obra postrera, escrita en las horas previas a su muerte, es una despedida que, al mismo tiempo, encierra un importante mensaje político, en unos momentos en que el pueblo filipino lucha y muere por la independencia de su patria. El Último Adiós, es su mensaje póstumo, así reflejado:

En campos de batalla, luchando con delirio,

Otros te dan su vida, sin dudas, sin pensar. 
El sitio nada importa: ciprés, laurel o lirio, Cadalso o campo abierto, combate o cruel martirio,

Lo mismo es si lo piden La Patria y el hogar.

Yo muero, cuando veo que el cielo se colora

Y al fin anuncia el día, tras lóbrego capuz;

Si grana necesitas, para teñir tu aurora, ¡Vierte la sangre mía, derrámala en buena hora,

Y dórela un reflejo de su naciente luz!.

No hay duda que trata de elevar la moral de los filipinos que luchan por la independencia del Archipiélago. Por ello, en la quinta estrofa, parece recurrir al antiguo "Dulce et decorum est pro patria mori", cuando, refiriéndose a Filipinas escribe:

Ensueño de mi vida, mi ardiente vivo anhelo, ¡Salud! Te grita el alma, que pronto va a partir, ¡Salud! ¡Ah, que es hermoso caer por darte vuelo,

Morir por darte vida, morir bajo tu cielo,

$Y$ en tu encantadora tierra la eternidad dormir!

El Último Adiós de Rizar y su ejemplo, sirvió de estímulo a los filipinos para ganar su propia patria. Su obra sentó las bases ideológicas para que Filipinas tuviera conciencia de su destino como nación. 


\section{Bibliografía}

La Solidaridad núm. 23 (Madrid, 15 de enero de 1890), artículo Ingratitudes.

La Solidaridad, septiembre de 1889-enero de 1890 (Filipinas dentro de Cien Años).

La Independencia, núm extrordinario de 25 de septiembre de 1898 dedicado a Rizal.

RETANA, W. E.: Vida y escritos del Dr. Rizal. Editorial Librería General de Victoriano Suárez. Madrid, 1907.

UNAMUNO, Miguel de: Epílogo a la obra anterior de Retana.

RETANA, W. E.: Rizal, noticias biográficas. Biblioteca Popular de L'AVENÇ, Barcelona, 1910.

RIZAL, José: Sucesos de las Islas Filipinas del Doctor Antonio de Morga. "Obra nuevamente sacada a la luz y anotada por José Rizal". Editorial Librería de Garnier Hermanos. París, 1890.

RIZAL, J osé: El Filibusterismo. Editorial MAUCCI. Barcelona, 1911.

RIZAL, J osé: Noli me tangere. Editorial AECI. Madrid, 1992. 